\title{
Clinical study of appropriate length artificial chordae tendineae implantation in Mitral Valve Replacement for rheumatic heart disease
}

\author{
Zulei Zhang ${ }^{1}$, Fajia Huํㄹ ${ }^{1}$ Wei Yang ${ }^{1}$, Yi Gong ${ }^{1}$, Chao Lu ${ }^{1}$, and Xiao Dong ${ }^{1}$ \\ ${ }^{1}$ Affiliation not available
}

September 21, 2020

\begin{abstract}
Abstract Background We aimed to investigate the clinical effect of implantation of artificial chordae tendineae with appropriate length in Mitral Valve Replacement (MVR) for rheumatic heart disease. Methods The clinical data of a total of 105 patients with rheumatic mitral stenosis who underwent MVR in the Second Affiliated Hospital of Nanchang University from July 2017 to July 2018 were analyzed retrospectively. According to whether the artificial chordae tendineae were implanted during the operation, the patients were divided into Mitral Valve Replacement with artificial chordae tendineae implantation group (experimental group, $\mathrm{n}=55$ ) and simple Mitral Valve Replacement group (control group, $\mathrm{n}=50$ ). Compared two groups of patients with early postoperative mortality and complications, postoperative cardiac structure and left ventricular function changes. Result Compared with the control group, the ascending aorta occlusion time, cardiopulmonary bypass time and operation time in the experimental group were slightly longer than those in the control group, but there was no significant difference between the two groups $(\mathrm{P}>0.05)$. One patient died early after operation in the control group and none in the experimental group. All patients had no complications such as prosthetic valve dysfunction, peri-valvular leakage and ventricular rupture. There were significant differences in left ventricular ejection fraction (LVEF), left ventricular end-diastolic diameter (LVEDD), left ventricular end-systolic diameter (LVESD) and cardiac function grade between the two groups at 5 days, 3 months and 1 year after operation. Conclusion Implantation of artificial chordae tendineae with appropriate length into MVR in patients with rheumatic heart disease can effectively maintain left ventricular function, reduce postoperative complications and improve postoperative quality of life. Keywords Rheumatic heart disease; Mitral Valve Replacement; Artificial chordae tendineae
\end{abstract}

\section{Hosted file}

manuscript.doc available at https://authorea.com/users/360458/articles/482158-clinicalstudy-of-appropriate-length-artificial-chordae-tendineae-implantation-in-mitral-valvereplacement-for-rheumatic-heart-disease

\section{Hosted file}

Figures.docx available at https://authorea.com/users/360458/articles/482158-clinicalstudy-of-appropriate-length-artificial-chordae-tendineae-implantation-in-mitral-valvereplacement-for-rheumatic-heart-disease

\section{Hosted file}

table.docx available at https://authorea.com/users/360458/articles/482158-clinicalstudy-of-appropriate-length-artificial-chordae-tendineae-implantation-in-mitral-valvereplacement-for-rheumatic-heart-disease 